\title{
Psychological factors in patients with chronic rheumatoid arthritis
}

Although there are clear anatomical and physiological changes in patients with chronic rheumatoid arthritis (RA), evidence is accumulating for the importance of psychological factors as determinants of disease development and of patients' ability to adapt to their condition. There is also an increasing awareness that arthritis treatment and education programmes car be improved by paying greater attention to the problems patients face in adapting to a chronic disease both physically and psychologically. ${ }^{1-5}$

There are inevitable problems in unravelling the cause and effect relationship between a chronic physical illness and psychological status. Premorbid personality may have a role in the development of arthritis-for example, unconscious or habitual coping preferences may identify individuals who tend to deny emotions and are more prone to experience somatic symptoms. The possibility that RA is associated with personality disorders has received considerable attention. ${ }^{6-8}$ Evidence takes the form of clinical reports and controlled investigations. ${ }^{910}$ Factors such as repressed hostility, ${ }^{11}$ poor marital, social, and vocational adjustment ${ }^{12}{ }^{13}$ and obsessive compulsive character structures ${ }^{14}$ are among some of the reported manifestations of psychological maladjustment in arthritic patients. After many years of disease, however, it may be difficult to distinguish between cause and effect.

The concept of repressed hostility was once thought to be particularly important. In 1958 Fisher and Cleveland found that patients with RA had considerable difficulty in expressing anger. ${ }^{15}$ Barchilon reported in 1963 the case of a young woman with RA who avoided translating her angry feelings into action by adopting muscular hypotonicity in areas of her body which later became the sites of rheumatoid symptoms. ${ }^{16}$ Further work by Cobb found that male patients with RA admitted to angry feelings to a lesser extent than control groups of their male relatives and patients with duodenal ulcer. ${ }^{17}$ Standard psychological tests have been used to characterise the personality profiles of arthritic patients. One of these is the Minesota Multiphasic Person- ality Inventory (MMPI), which consists of 566 true/false statements which comprise three validity scales and 10 clinical scales. It was completed by 35 women and 10 men with RA. ${ }^{18}$ Repressed hostility did not emerge as a special problem in this group, but the authors reported that patient profiles resembled the classical neurotic pattern with raised hypochondriasis, depression, and hysteria scales. The MMPI has been used by several other authors to assess arthritic patients, ${ }^{19-21}$ and reports all record an increase in these three scales, suggesting an association between personality and physical disease and leading some to believe depression plays an important part in RA.

Recently, Pincus et al looked more closely at this association and explored the possibility that increased scores on the MMPI hypochondriasis, depression, and hysteria scales in patients with RA might result from the structure of the questionnaire, rather than from psychological disorders. ${ }^{22}$ They asked 18 rheumatologists to identify which of the 117 statements that contribute to these three MMPI scales would be answered differently by patients with RA simply because of the presence of RA and without regard to psychological status. They picked out five items on which there was general agreement among the rheumatologists and reviewed the responses given by the patients to these items. Most patients had indeed given a positive response. Furthermore, these responses were almost exclusively responsible for the abnormally high scores on the various scales, and when only other, non-RA related items on the scales were considered, patients with RA showed the same response as normal controls. This must raise serious doubts about the use of the MMPI in arthritic patients, and it seems clear that to study this area further an instrument is required to assess reliably psychiatric disorder in patients with somatic complaints resulting from various medical conditions, including arthritis.

Goldberg, Zigmond and Snaith have addressed this problem and developed the Hospital Anxiety and Depression (HAD) scale. ${ }^{23} 24$ This one page questionnaire presents 14 statements about 
how the subject has been feeling in the past week-for example, 'I still enjoy the things I used to enjoy'-and offers a choice of replies-for example, 'Definitely as much; Not quite as much; Only a little; Hardly at all'. Scoring is straightforward and provides numerical values for depression and anxiety, each on a $0-21$ scale. The normal range is 8-10. We have administered the HAD to inpatients undergoing a flare of their RA and identified many with greater degrees of depression and especially anxiety than occur in healthy people (unpublished data).

A further area which may be of psychological importance is the effect of the unpredictable nature of remission and exacerbation in RA. Nicassio et al postulated that this uncertainty may lead to feelings of personal helplessness and passive resignation. ${ }^{25}$ They also suggested that patients who learn to tolerate the unpredictable nature of RA may be able to achieve better control of their disease. To test their ideas, they developed a 15 item scale-the Arthritis Helplessness Index (AHI) - to assess patients' perception of helplessness in coping with arthritis. They found that greater helplessness correlated significantly with greater age, lesser education, lower self esteem, higher anxiety and depression, and impairment in performing activities of daily living as measured by the Health Assessment Questionnaire. ${ }^{26}$ Furthermore, changes in helplessness correlated with changing difficulty in performing activities of daily living over one year. The inclination of some patients (perhaps supported by the atmosphere of much current medical practice) to hand over responsibility for disease to doctors militates against a sense of personal control and self motivation, suggesting that inappropriate doctorpatient relationships may aggravate chronic disease and that, at least for some patients, disease management could be more effective in group settings.

Despite the methodical difficulties there can be little doubt about the importance of psychological factors in the way patients cope with their arthritis and in treatment and education programmes. McFarlane and Brooks recently assessed 30 patients with RA over a three year period and found that psychological factors consistently predicted more of the variance in disability than did disease activity. ${ }^{27}$ They also reported that these factors were associated with a tendency to deny the emotional dilemmas caused by having a chronic illness, difficulty in accepting doctor's reassurances, and clinical depression. Their findings led the authors to suggest that the prognosis for future functional ability may only be formulated when the patient's attitudes and psychological state are carefully assessed. In 65 patients with hip and knee osteoarthritis Summers and colleagues also concluded that psychological variables were strong indicators of individual differ- $-\frac{\omega}{.}$ ences in functional impairment and pain. ${ }^{28} \mathrm{~A}$ recent $\overrightarrow{\vec{F}}$ : randomised controlled study of psychological therapy in 53 patients with RA suggested that pain, $\frac{}{c}$ anxiety, and disease activity might be reduced, an 음 effect attributed principally to relaxation therapy. ${ }^{29} \frac{\mathrm{N}}{\overline{\mathrm{D}}}$

These reports may be of particular importance $\stackrel{\Phi}{\circ}$ when patient education programmes are being $\%$ developed for those with chronic diseases such as $\vec{O}$ RA. Publications in this field have increased, ${ }^{30-32}$ ? but educational objectives rarely include an attempt $\vec{\omega}$ to change more than the patients' knowledge. The evidence suggests that knowledge alone will rarely improve health ${ }^{33-35}$ and it seems likely that patients will also need to acquire skills to cope with specific $\overrightarrow{-}$ aspects of their illness (such as a flare in a specific joint) together with an appropriate attitude to their 8 disease, which will enable them to apply theiro knowledge and skills and take a greater control of their own management. Psychological assessment, $\vec{\nabla}$ perhaps using the HAD and AHI, will form an important part of the assessment of the effectiveness of any realistic educational intervention.

Rheumatology Unit, Department of Medicine, Bristol Royal Infirmary

Bristol,

BS2 8HW

*Correspondence to Dr John R Kirwan.

†Current address: Casualty Department, John Radcliffe Hospital, $\overrightarrow{\vec{r}}$ Headington, Oxford OX3 9DU.

We thank Dr Vanja Orlans, Stress Research and Control Centre, Birkbeck College, for her helpful comments.

\section{References}

1 Brooks P M, McFarlane A C. Total patient management in RA. Med J Aust 1983; 1: 393-4.

2 Jette A M. Improving patient co-operation with arthritis. $\delta$ Arthritis Rheum 1982; 25: 447-53.

3 Rogers M P, Laing M H, Partridge A J. Psychological care of adults with RA. Ann Intern Med 1982; 96: 445-58.

4 Rogers M P, Reich P, Kelly M J, Laing M H. Psychiatric $D$ conditions among hospitalised arthritis patients. Gen Hosp 을.
Psychiatry 1980; 2: 89-94.

5 Meenan R F, Yelin E, Nevitt M, Epstein W V. The impact of $N$ chronic disease: sociomedical profile of RA. Arthritis Rheum 1981; 24: 544-9.

6 King S H. Psychosocial factors associated with RA: a literature review. J Chronic Dis 1955; 2: 287-302.

7 Scotch M A, Geiger H J. The epidemiology of RA. A review with attention to social factors. J Chronic Dis 1962; 15: 1037-67.6

8 Mueller A D, Lefkovits A, Bryant J E, Marshall M L. Some $\frac{c}{\Phi}$ psychosocial factors in RA. Arthritis Rheum 1961; 4: 275-82. @

9 Cormier B M, Wittkonen E D. Psychosocial aspects of RA. Canad Med Assoc J 1957; 77: 533-41.

10 Cleveland S E, Fisher S. Behaviour and unconscious fantasies of patients with RA. Psychosom Med 1954; 16: 327-33. 
11 Cobbs S. Contained hostility in RA. Arthritis Rheum 1959; 2: 419-26.

12 Mueller A D, Lefkovits A M. Personality structure and dynamics of patients with RA. J Clin Psychol 1956; 12: 143-7.

13 Cobbs $S$, Miller $M$, Wieland $M$. On the relationship between divorce and RA. Arthritis Rheum 1959; 2: 415-8.

14 Gildea E F. Special features of personality which are common to certain psychosomatic disorders. Psychosom Med 1949; II: 273-81.

15 Fisher S, Cleveland S E. Body image and personality. Princeton: Van Nostrand, 1958.

16 Barchilon J. Analysis of a woman with incipient RA. Int J Psychoanal 1963; 44: 163-77.

17 Cobb S. The epidemiology of RA. Vol. 9. New Jersey: Acad Med, 1963: 52-60.

18 Nalven F B, O'Brien J F. Personality pattern of RA patients. Arthritis Rheum 1964; 7: 18-28.

19 Moos R H, Solomon G F. MMPI response pattern in patients with RA. J Psychosom Res 1964; 18: 17-28.

20 Polley H F, Swenson W M, Steinhilber R M. Personality characteristics of patients with RA. Psychosomatics 1970; 11: 45-9.

21 Liang M H, Rogers M, Larson M, et al. The psychosocial impact of SLE and RA. Arthritis Rheum 1984; 27: 13-19.

22 Pincus T, Leight F C, Bradley A L, et al. Elevated MMPI scores for hypochondriasis, depression and hysteria in a patient with RA reflect disease rather than psychological status. Arthritis Rheum 1986; 29: 1456-66.

23 Goldberg D. Identifying psychiatric disease among general medical patients. Br Med J 1985; 291: 161-2.

24 Zigmond A S, Snaith R P. The hospital anxiety and depression scale. Acta Psychiatr Scand 1983; 67: 361-70.
25 Nicassio M P, Wallston A K, Callahan L F. The management of helplessness in RA. The development of the Arthritis Helplessness Index. J Rheumatol 1985; 12: 462-7.

26 Fries J F, Spitz P W, Young D Y. The dimensions of health outcomes: the health assessment questionnaire, disability and pain scales. J Rheumatol 1982; 9: 789-93.

27 McFarlane A C, Brooks P M. Determinants of disability in RA. Br J Rheumatol 1987; 26: 101-8.

28 Summers M N, Haley W E, Reveille J D, Alarcon G S. Radiographic assessment and psychologic variables as predictors of pain and functional impairment in osteoarthritis of the knee or hip. Arthritis Rheum 1988; 31: 204-9.

29 Bradley L A, Young L D, Anderson K O, et al. Effects of psychological therapy on pain behavior of rheumatoid arthritis patients. Arthritis Rheum 1987; 30: 1105-14.

30 Rippey R M, Bill D, Abeles M, et al. Computer based patient education for older persons with osteoarthritis. Arthritis Rheum 1987; 30: 932-5.

31 Spiegel T M, Knutzen K L, Spiegel J S. Evaluation of an inpatient rheumatoid arthritis patient education program. Clin Rheumatol 1987; 6: 412-6.

32 Lorig K, Lubeck D, Kraines R G, Seleznick M, Holman H. Outcomes of self-help education for patients with arthritis. Arthritis Rheum 1985; 28: 680-5.

33 Mazzuca S A. Does patient education in chronic disease have therapeutic value? J Chronic Dis 1982; 35: 521-9.

34 Williams $\mathrm{G} \mathrm{H}$, Wood $\mathrm{O} \mathrm{H} \mathrm{N}$. Common-sense beliefs about illness: a mediation role for doctors. Lancet 1986; ii: 1435-6.

35 Affleck G, Pfeiffer C, Tennen H, Fifield J. Attributional processes in rheumatoid arthritis patients. Arthritis Rheum 1987; 30: 927-31. 